2) Ehni, G.: J. Neurosurg., 31, 490, 1969.

3) Ehni, G.: J. Neurosurg., 31, 507, 1969.

4) Epstein, J. A. : J. Neurol. Neurosurg. Psychiat. 25, 165, 1962.

5) 平光・ほか: 整形外科. $25,745,1974$.

6) 蓮江・ほか: 整形外科. $25,755,1974$.

7) 栗原・ ほ整形外科. 23, 202, 1972.

8）片岡・ほか：中部整災誌. 16, 835, 1973.

9） 円尾・ほ加：整形外科. 25, 755, 1974.

10）酒句・ほか：整形外科と災害外科. 24, 417, 1975.

11) Schatzker, J. et al. : J. Bone Joint surg., 50-B, 606, 1968.

12) Teng, P. et al.: Arch. Neurol., 8, 221. 1963.

13）竹光・ほか：中部整災誌. 16, 837, 1973.

14) Verbiest, H.: J. Bone Joint Surg., 36-B, 230, 1954.

15) Verbiest, H.: J. Bone Joint Surg., 37-B, $576,1955$.

16) Wilson, C. B. : J. Neurosurg. 31, 499, 1969.
17）若松・ほか：整形外科. 21, 1, 1970.

18）山田・ほ加：整形外科. $21,8,1970$.

翼 問山口大 服部 奖

昌趾に難治性濽瘍を呈した症例では，下肢の血管性 疾患はなかったのですか.

解 答麇児島大学 酒包 崇

下肢部の動脈血行不全は認められなかった。

質 問 九大整形 角的 信昭

Canda の瘾着と Lumbar spinal stenosis との関 連性があるか否か先生の御考えは?

解 答廐児島大学 酒旬 崇

癒着の所兒はミクログラムの閉塞の著明なもので 7 人の中 6 人にみられている.

\title{
腰部脊椎管狭窄について術後馬尾神経障害と 再発をくり返した症例について
}

熊本大学医学部整形外科学教室

$\begin{array}{lllllll}\text { 森 } & \text { 田 } & \text { 秀 } & \text { 明・成 } & \text { 尾 } & \text { 政 } & \text { 图 } \\ \text { 小 } & \text { 柳 } & \text { 英 } & \text { 一・前 } & \text { 川 } & \text { 清 } & \text { 継 } \\ \text { 栄 } & & \text { 輝 } & \text { 己・浦 } & \text { 門 } & & \text { 操 }\end{array}$

Investigation of Poor Cases after Operation for the Lumbar Spinal Stenosis

By

H. Morita, M. Naruo, E. Koyanagi, K. Maekawa,

T. Sakae and M. Urakado

Department of Orthopedic Surgery, Kumamoto University

Medical School, Kumamoto

We have a series of 110 patients with lumbar spinal stenosis who were treated by surgical procedure from September 1971 to March 1976.

In these series 4 cases revealed poor results. Poor cases and their causes are suggested as follows ;

1. A 42-year old woman with degenerative stenosis increased cauda equina lesion after operation with some recovery following wide laminectomy and facetectomy.

This case seemed to be caused in further damage of cauda equina due to transdural 
nucleotomy through so-called key-hole laminotomy.

2. A 62-year old woman with degenerative stenosis and scoliotic deformity developed a postoperative hemorrhage causing cauda equina paralysis owing to the unstable hypertension with only slight recovery following removal of the blood clot and extensive laminectomy.

3. A 66-year old woman with $\mathrm{L}_{4}$ spondylolisthesis had saddle anaesthesia following decompressive laminectomy without spinal fusion with gradual recovery of saddle anaesthesia. In this case anterior approach seemed to have been better procedure.

4. A 47-year old woman with post-laminectomy stenosis had twice recurrence during 3 years.

This case seemed to be caused in inadequate decompressive laminectomy and facetectomy owing to the prominent heaping of facets and hyperplasia of neural arches.

われわれが大学ならびに 関連病院において 昭和 46 年 9 月から昭和 51 年 3 月 までに 観血的治療を施行し た腰部脊椎管狭窄の症例は，110 例に達する．その分 類と頻度は表 1 に示す. 然しながら本症に対する術後 成績は, 必ずしも全例予後良好乞は言い難人, われわ れは術後症状の増悪を認めた 3 例ならごに再発をくり 返した 1 例を経験したので症例の概略を報告し考察す る.

\section{表 1 (S.46.9. - S.51.3.)}

Lumbar Spinal Canal Stenosis (Classification of Operated Cases)

Developmental Stenosis

Degenerative Stenosis 78(71\%)

Spondylolisthetic Stenosis..... $14(13 \%)$

Pseudospondylolisthetic Stenosis … 9( $8 \%$ )

Post traumatic Stenosis …….......... 3( $3 \%$ )

Scoliosis Stenosis ......................... 3( $3 \%)$

Iatrogenic Stenosis $3(3 \%)$

110

症例 1.42 才, 女性, 事務員.

主訴: 腰痛, 左下肢痛.

既往歴：29才時虫秉炎手術.

家族歴：特になし。

現病歴：10 年来の腰痛で種々保存的治療を受ける も軽快せず，昭和 36 年: 11 月右 $L_{5}$ 横突起と腸骨の fusion を受けて症状緩解. 38 才時再度腰痛出現し， 41 才時には, 腰痛, 右下肢痛増強し, 同時に急に起 立步行不能となり, 某医に入院, 昭和 46 年 6 月当科 飞転入院.

入院時所見 : 表 2 参照.

ᄂ線所見: 右 $\mathrm{L}_{5}$ 横突起 之腸骨瘾合, 側彎変形, $\mathrm{L}_{3-4,4-5}$ 椎間板狭小不整, 退行性変化等を認め春“椎静
脈造影では, $\mathrm{L}_{4-5}$ 間両側性に 椎間静脈前内椎骨静脈 叢の欠損, $\mathrm{L}_{5}-\mathrm{S}_{1}$ 間右前内椎骨静脈叢欠損し, 外椎骨 静脈叢の異常吻合を認める.ミエログラムは, 前後像 で $\mathrm{L}_{3-4}$ 以下の狭窄, 馬尾神経レリーフ像, 側面像で も前後方向より圧迫像, 前屈位で軽くなるが, 狭小が ある. 昭和 46 年 7 月いわゆる key-hole Laminotomy, transdural Nucleotomy $\left(\mathrm{L}_{3-4}, 4-5\right.$ hard disc $)$ 施行. 術後 Cauda equina の不全麻瘨, $L_{1}$ 以下の 知覚障害出現. 術後回復不十分のため昭和 46 年 12 月 $\mathrm{L}_{3-4-5}$ Wide laminectomy, facetectomy 施行し昭 和 47 年 7 月 $\mathrm{L}_{4}$ 以下に Hypesthesia を残して, 左 SLB を装䏚し杖歩行にて退院.

症例 2.62 才, 女性, 主婦.

主訴: 腰痛, 右下肢痛.

既往歴：20 才時虫垂炎手術，57 才時高血圧症，自 律神経失調症.

家族歴：父食道癌，母脳卒中にて死亡.

現病歴：以前より腰痛あり。昭和 50 年 1 月腰痛, 右下肢痛増強, $200 \mathrm{~m}$ 程の歩行で有間歇性跛行出現 し, 某医で加療. 昭和 50 年 3 月当科入院.

入院時所見 : 表 2 参照.

ᄂ 線所見： $L_{2-3}$ を頂椎とする側彎変形と退行性変 化. $\mathrm{L}_{1-2}, 2-3,4-5$ 椎間板不整で回施を伴う。ミエ、ログ ラム表 3 参照. Lumbar spinal stenosis として昭和 50 年 3 月 Wide laminectomy $\left(\mathrm{L}_{3-5}, \mathrm{~S}_{1}\right.$ 一部) facetectomy 施行. しかし術後より高血圧と頻脈, 呼吸 困難出現すると共に, Cauda equina paralysis を認 めた。 高血圧之頻脈の治潦を行ない, 回復不十分のた め，14日後 Wide laminectomy $\left(\mathrm{L}_{1-2}\right)$ を追加除圧 し, 一部硬膜を圧迫する凝血塊を喼めた。術後 Motor, Sensory 共徐々に回復を認め, Saddle anaesthesia を残し，丽側 SLB 装用し，松葉杖歩行で昭和 51 年: 
表 2

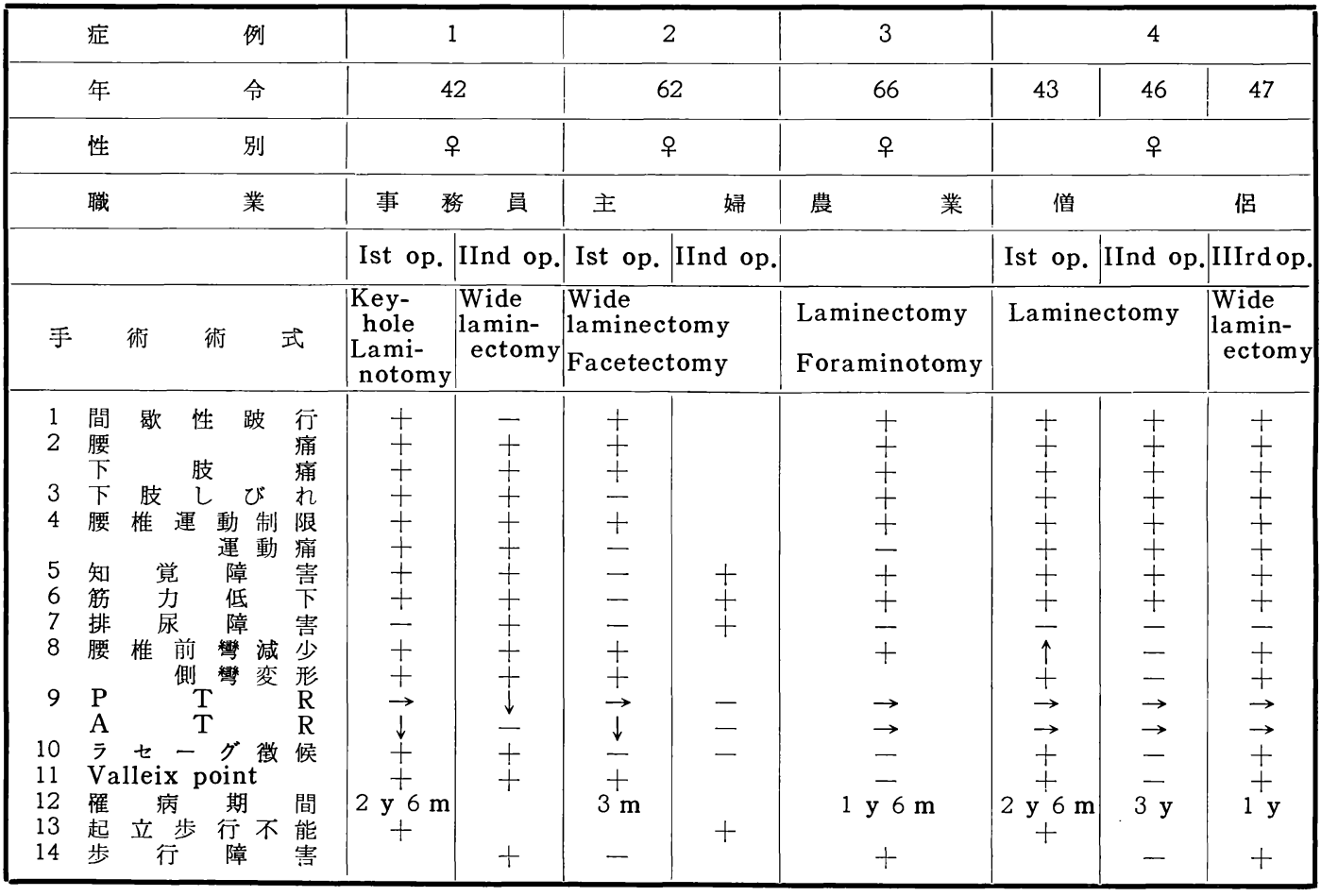

表 3

\begin{tabular}{|c|c|c|c|}
\hline 症例 & ミエログラム & 椎弓切除範囲 & 再 手 術 所 見 \\
\hline 1 & 完 全停 止 像 & $\mathrm{S}_{1} \mathrm{~L}_{3-5}$ 部 & $\begin{array}{l}\text { 術後瘢痕組織が後方後外側から Cauda equina 圧迫, Dural pulsa- } \\
\text { tion 徽弱出現する }\end{array}$ \\
\hline 2 & 完 全 停 止 像 & $\mathrm{L}_{1-5}$ & $\begin{array}{l}\text { 硬膜外腔に hematoma 充満 } \\
L_{2-3} \text { 部 Dura に blood clot によるE痕 } \\
\text { Dural pulsation 出現 }\end{array}$ \\
\hline 4 & $\begin{array}{l}\text { 後方より絞扼像 } \\
\text { 根像 欠 損 }\end{array}$ & $\begin{array}{l}\mathrm{L}_{4} \\
\mathrm{~L}_{5} \rightarrow \text { 部 }\end{array}$ & 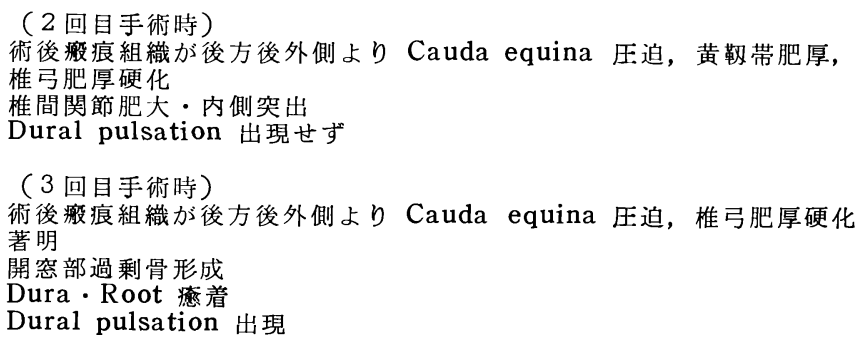 \\
\hline
\end{tabular}

5 月退院.

症例 3.66 才, 女性, 農業.

主訴：喓痛, 両下肢痛.

既往歴：高血圧症.

家族歴：特になし.
現病歴：若い頃より腰痛がありハリ治療をしていた が, 明和 48 年頃より疼痛のため不自由を感じ出し, 炤和 49 年 3 月より腰痛, 下肢痛増強, 約 5 分間の歩 行で間歇性跛行出現. 某医で加療するも不変のため, 昭和 49 年 6 月当科入院. 
入院時所見 : 表 2 参照.

レ線所見 $: \mathrm{L}_{4}$ 分離之一り $\oplus$, 迄り率は前屈位 $25 \%$, 中間位 $18 \%$, 後屈位 $23 \%$ \% $\mathrm{L}_{4-5}$ 間前屈で前縁つぶれ $\oplus$, traction spur は㷫めない. ミエログラム；表 3 参照. 昭和 49 年 6 月 Laminectomy $\left(\mathrm{L}_{4-5}, \mathrm{~L}_{3}\right.$ 一部) Foraminotomy 施行. 術後より Saddle region の hypesthesia, anesthesia 出現し, paresthesia を伴 う排尿障害を認め, Cystometry では低圧膀胱最高意 識圧の低下を恋めた。会陰部に $\frac{2}{10} \sim \frac{5}{10}$ の hypesthesia を残し昭和 49 年 10 月退院. 昭和 51 年 3 月現在 ほとんど知覚障害を認めない。

症例 4.47 才, 女性, 僧吕.

主訴：腰殿部痛, 左下肢痛.

既往歴: 20 才時虫垂炎手術. 32 才時遊走腎手術. 46 才時 CSR にて手術.

家族歴：両親共脳出血で死亡.

現病歴：10 年来の腰痛あり 40 才より増弦， 42 才時 左下肢痛, 間歇性跛行出現し昭和 46 年 2 月には起立 歩行不能となり，3 月某医入院加療，4月当科入転入 院した。

入院時所見：表 2 参照.

ᄂ 線所見: $\mathrm{L}_{5}-\mathrm{S}_{1}$ 間椎間板狭小, $\mathrm{L}_{5}-\mathrm{S}_{1}$, facets 不 整, 硬化, $\mathrm{L}_{5}-\mathrm{S}_{1}$ 間椎弓間腔軽度狭小. ミエログラ 么; 前後像で $\mathrm{L}_{5}-\mathrm{S}_{1}$ 間左久損, 左: $\mathrm{S}_{1}$ 根像欠損, 左斜 位像でも $\mathrm{L}_{5}-\mathrm{S}_{1}$ 間久損.

椎間板造影像： $\mathrm{L}_{4-5}$ 間で中等度変性, post. protrusio がみられ $\mathrm{L}_{5}-\mathrm{S}_{1}$ 間で高度変性がみられ pain rasponse は陽性であった. 昭和 46 年 5 月椎間板へル ニアとして, Laminectomy $\left(\mathrm{L}_{5}, \mathrm{~S}_{1}\right.$ 一部) を行ない, 黄靶帯, 椎間孔近くの Spur 切除した. 同年 7 月退院 したが，明和 49 年 5 月より再発し，同年 6 月再入院し た. iatrogenic stenosis 0 診断で同年 7 月 Laminectomy $\left(\mathrm{L}_{4-5}\right)$ Foraminotomy 施行し, 同年 8 月退 院した. 昭和 50 年 7 月症状再発. 昭和 51 年 1 月入院 し.同月 Wide laminectomy $\left(\mathrm{L}_{4}, \mathrm{~L}_{5}\right.$ 一部), Facetectomy 施行し 2 月退院した.

\section{考 察}

Lumbar Spinal Stenosis において, Paine ${ }^{2)} ら$ （1976）は, 術後出苒により Cauda equina の圧迫 を生じ, Evacuation により，少し回復した 1 例と術 後 Cauda equina lesion が増墨した 2 例を報告して いる. Schlesinger \& Taveras ${ }^{9)}$ (1953) は手術時 traumatic paralysis がよく生じ，てれは narrow canal の構造的特徵の認識不足によると整告してい る. また Clark ${ }^{6)}$ (1969) は, purely interlaminal approach や, limited laminectomy で root を探 索すると, Cauda equina damage があると警告し， Tile $^{3)}$ (1976) らは, すべての lumbar pain problem に対するいわゆる key-hole laminotomy は非難され るべきであると指摘している. われわれの症例 1 で は, 一時的にしろ起立歩行不能となる程の Cauda equina lesion があり, 易損性を具偖していると考え られる所へ, Key-hole laminotomy を施行し，さら に transdural に Nucleotomyしたととにより，損 傷を与えた可能性がある. また症例 2 では，々クログ ラムで欠損があり，側彎変形の頂椎にあたる $\mathrm{L}_{2}$ 椎弓 を残して除圧した所へ, 術後併発した高血圧により拍 車をかけたと思われる出血による凝血塊形成により, Cauda equina の圧迫をもたらしたと推定出来る. また Ehni ${ }^{5)}$ (1969) Clark ${ }^{6)}$ (1976) は，麻酔下に腰 椎前彎強制体位のため, 手術後 Cauda equina の急 性麻瘏例を報告して警告しでいるが，われわれの症例 では相当しない. 症例 3 の吂り症例では, 幸いにも Saddle anesthesia は回復したが，不安定性のある 所への後方侵㢣に問題があり, 今後脊椎不安定性の問 題ぶ残る. fusion の通否につき議論のある所である が, 症例 3 では明らかに不安定性が存在するので経過 をみて, fusion の必要性があろう。 iatrogenic lumbar spinal stenosis については Schatzker and Pennal ${ }^{4)}$, 进江, 岡田, 渡辺, 越前谷らの報告をみる が, Alexander and Brodsky ${ }^{7)}$ らは, post-laminectomy stenosis に関与する压迫因子を $5 つ$, 解剖学 的特徽について 8 つの因子を举げているが, 症例 4 に おいては, 不十分な除圧, facets の肥大と内側突出, 椎弓の異常な肥厚之硬化, 黄靶帯の肥厚, 病理組織学 的にも認めた非特異性炎症による㿂痕形成，開空部の 新生滑形成等が压迫因子と考えられる，硬膜，神経根 の瘾着を伴ない，異常に硬くて肥厚した laminae， facets に対与る除圧術は，サージェアートームなし には不可能である. また症例 4 では $\mathrm{L}_{5}$ Laminectomy 籁国が狭小なため, 将来の再発の危険性を保有してお り，今後経過観察しなければならない。

以上直接の要因を決めるのは困難であるが少なくと も何らかの iatrogenic factor が発症を早め, 再発 を絽り返したと考えられる，また，注目すべきは，絞 
扼された Cauda equinaにはその循環系に框当の障 害を所有しているととが, 一時的にも起立歩行不能と なるととからも推察され，その易損性を具備している 可能性が考えられる. この事は Lumbar Spinal Stenosis の除圧術の時，心すべき事である.

$$
\text { ま と め }
$$

Degenerative Lumbar Spinal Stenosis で術後 Cauda equina paralysis を生じた 2 例, Spondylolisthesis による Stenosis の術後に Saddle anesthesia を生に゙た 1 例, post-laminectomy stenosis で再発をくり返した 1 例, 計 4 症例を報告し, その要 因につき文献的考察を行なった。

\section{文献}

1) Brodsky, Alexander E., M. D.: Clinical Orthop. Relat. Research. No. 115, 116-121, 1976.

2) Clark, Kemp, M. D. : J. Neurosurgery, Vol. 31, 495-498, Nov. 1969.

3) Ehni, George, M. D. : J. Neurosurgery, Vol. 31, 490-494, 507-512, Nov. 1969.

4) Epstein, Joseph A., Epstein, Bernard S., and Lavine, Leroy: J. Neurol. Neurosurgery Psychiat., 25, 165-176, 1962.

5) Paine, K. W. E., M. B., F. R. C. (C) : Clinical Orthopaedics and Related Research. No. 115, 96-100, March-April, 1976.

6) Pennal, George F., M. D., M. Ch., F. R. C. S., and Schatzker, Joseph, M. D., B. Sc., F. R. C. S.: Clinical Neurosurgery, Vol.
18, 86-105, 1970.

7) Schatzker, Joseph and Pennal, George F., Toronto, Ontario, Canada: J. Bone Jt. Surg. Vol. 50-B, No. 3, 606-618, August, 1968.

8) Tile, Marvin, M. D., B. Sc. (Med.), F. R. C. S. (C), McNeil Stuart R., M. D., F. R. C. S. (C), Zarins, Raymond K., M. D., F. R. C. S. (C), Pennal, George F., M. D., M. Ch. (Orth.) F. R. C. S. (C), and Garside, S. Henry: Clinical Orthopaedics and Related Research. No. 115, 104-108, March-April, 1976.

9) W1tise, Leon L., M. D., Kirkaldy-Willis, W. H., M. D., F. R. C. S. (C), F. R. C. S. (E) and G. W. D. McIvor, M. D., F. R. C. S. (C): The treatment of spinal stenosis. Clinical Orthopaedics and Related Research. No. 115, 83-91, March-April, 1976.

\section{問 山口大学整形 小山 正信}

一番最初のスライドで, developmental stenosis が 70 数列ありと示されたように思いましたが，どの ようなものを developmental stenosis としておら れるか教えて下さい.

\section{追 加 九大整形 角田 信昭}

Spodylotic type の stenosis 例で, wide laminectomy 後, Spondylolysis を発生した例を経験し 江. 固定の問題および la minectomy の範囲との関連 についての先生の御考えは如何. また，そのような例 の経験はありませんでしたか. 